\title{
Synthesis and Growth Mechanism of Net-like Titanate Nanowire Films via Low-temperature and Low-alkali-concentration Route
}

\author{
Xinwen Huang ${ }^{1,2}, \quad$ Zongjian Liu ${ }^{1, *}$
}

(Received 14 March 2013; accepted 19 April 2013; published online 28 April 2003)

\begin{abstract}
Net-like titanate nanowire films can be grown on Ti substrates by non-hydrothermal treatment of $\mathrm{Ti}$ foils in alkali- $\mathrm{H}_{2} \mathrm{O}_{2}$ aqueous solutions with a low alkali concentration of $2 \mathrm{M}$ at $60-80^{\circ} \mathrm{C}$. The growth mechanism of such films has been investigated by identifying the role of both $\mathrm{H}_{2} \mathrm{O}_{2}$ and alkali in the nanowire formation and capturing the film morphology at early growth stages. It is found that the presence of $\mathrm{H}_{2} \mathrm{O}_{2}$ is necessary for the nanowire growth, and sufficient amount of $\mathrm{H}_{2} \mathrm{O}_{2}$ is needed to produce well-shaped nanowires. The nanowire growth is also strongly dependant on the alkali used, and nanowire films are formed only when metal hydroxides which can react with $\mathrm{TiO}_{2}$ to form layer-structured titanates are chosen. Our results have also revealed that the heterogeneous deposition of titanate on $\mathrm{Ti}$ substrate results in the growth of titanate sheets, and the nanowire formation is via a splitting process by which each titanate sheet gradually evolves into nanowire thin layer. Based on the experimental results, a detailed mechanism is proposed for the growth of titanate nanowire films in alkali- $\mathrm{H}_{2} \mathrm{O}_{2}$ aqueous solutions at low temperature.
\end{abstract}

Keywords: Nanostructured materials; Nanowires; Synthesis; Thin films; Titanate

Citation: Xinwen Huang and Zongjian Liu, "Synthesis and Growth Mechanism of Net-like Titanate Nanowire Films via Low-temperature and Low-alkali-concentration Route", Nano-Micro Lett. 5(2), 93-100 (2013). http://dx.doi.org/10.5101/nml.v5i2.p93-100

\section{Introduction}

Owing to their high length-to-diameter ratio and large specific surface area, one-dimensional (1D) materials, e.g., nanotubes and nanowires, exhibit unique mechanical, physical, or chemical properties and have found applications in many fields, such as electronics, catalysis, and sensors. 1D titanate nanostructures are of great scientific and technical interest because of their photocatalytic activities and interesting ion-exchange/intercalation properties [1-4]. They have shown promising applications in photocatalytic degradation of organic pollutants $[1,2]$, adsorption for radioactive or heavy metal ions [4], solar energy conversion [5], electrochromism [6], and gas sensing [7].
Since the properties of titanate nanostructures are often related to their morphology, the synthesis of titanate nanostructures with desired 1D shape is key to improve their applications. As one of the most effective methods for preparation of $1 \mathrm{D}$ titanate nanostructures, the method of hydrothermal treatment of $\mathrm{TiO}_{2}$ in concentrated alkali solutions has gained great attention [8-13] since the pioneering work of Kasuga et al. [14]. In general, under relatively lower temperature (e.g. $\left.\leq 160^{\circ} \mathrm{C}\right)$ and lower alkali concentration (e.g. $5-10 \mathrm{M})$ nanotubes are formed whereas higher temperature (e.g. $200^{\circ} \mathrm{C}$ ) and higher alkali concentration (e.g. $15 \mathrm{M}$ ) or using a rotating autoclave [9] favors the formation of nanowires. In recent years, the extension of such hydrothermal method to treatment of Ti foils

\footnotetext{
${ }^{1}$ Resource \& Environment Catalysis Institute, College of Chemical Engineering and Materials Science, Zhejiang University of Technology, Hangzhou, 300014, P. R. China

${ }^{2}$ College of Biological and Environmental Engineering, Zhejiang University of Technology, Hangzhou, 300014, P. R. China

*Corresponding author. Tel./fax: +86-571-88320973. E-mail: zjliu@zjut.edu.cn
} 
for fabricating titanate nanotube or nanowire films on Ti substrates has also been aroused increasing interest [15-22] because the formed films can be directly used as photoanodes for photocathodic protection for stainless steel [22] or converted to $\mathrm{TiO}_{2}$ films for water splitting [20] and decomposition of harmful compounds [21]. For example, Yada et al. have reported that titanate nanotube films can be formed on Ti substrates by hydrothermal treatment of Ti foils in $10 \mathrm{M}$ $\mathrm{NaOH}$ solutions at $160^{\circ} \mathrm{C}[16,17]$. Similar studies on the formation of titanate nanotube films via hydrothermal treatment method have also been reported by a number of other research groups [15,18-22]. Recently, $\mathrm{Hu}$ et al. have treated $\mathrm{Ti}$ foils in $10 \mathrm{M} \mathrm{NaOH}$ solutions at $180^{\circ} \mathrm{C}$ in the presence of oxidative organic compounds and found that titanate nanowire films, rather than nanotube films, are formed [21].

While the method of hydrothermal treatment in concentrated alkali solution is routinely used to produce titanate nanotube or nanowire films on Ti substrates, little attention has been paid into another approach, namely non-hydrothermal (or low-temperature) treatment in alkali- $\mathrm{H}_{2} \mathrm{O}_{2}$ mixed solutions [23,24]. Wu et al. first reported that titanate nanowires could be synthesized by treating Ti foils in a 1:1 (v/v) mixture of $10 \mathrm{M}$ $\mathrm{NaOH}$ and $30 \%(\mathrm{v} / \mathrm{v}) \mathrm{H}_{2} \mathrm{O}_{2}$ at a temperature of $80^{\circ} \mathrm{C}$ [23]. More recently, we have studied the effect of alkali concentration on the formation of titanate nanowire films by treatment of $\mathrm{Ti}$ foils in $\mathrm{NaOH}-\mathrm{H}_{2} \mathrm{O}_{2}$ mixed solutions with a $\mathrm{H}_{2} \mathrm{O}_{2}$ concentration of $15 \%(\mathrm{v} / \mathrm{v})$ at $80^{\circ} \mathrm{C}$ and found that a mixed solution with a much low $\mathrm{NaOH}$ concentration (namely $2 \mathrm{M}$ ) can be used to produce well-shaped net-like titanate nanowire films [24]. Despite these limited efforts, however, the key issue, namely the formation mechanism of the nanowire film, is still not clear. Wu et al. have assumed that the formation of nanowires is a result of decrease in the surface energy via crystallization of amorphous titanate sheets along one direction [23], but there is no direct evidence for this assumption. In the present work we report the clear observation of the growth of titanate sheets on $\mathrm{Ti}$ substrate via heterogeneous deposition and the conversion of each titanate sheet to nanowire layer via a "splitting" process. By identifying the role of both $\mathrm{H}_{2} \mathrm{O}_{2}$ and alkali in the nanowire formation, a detailed growth mechanism is proposed for low-temperature growth (60$80^{\circ} \mathrm{C}$ ) of titanate nanowire films in alkali- $\mathrm{H}_{2} \mathrm{O}_{2}$ solutions of low alkali concentration (2 M).

\section{Experiment}

Ti pieces of $4.80 \times 1.30 \times 0.4 \mathrm{~mm}^{3}$ in size were polished with abrasive paper, degreased in a mixed solution of $\mathrm{NaOH}$ and $\mathrm{Na}_{2} \mathrm{CO}_{3}$ (the ratio of $\mathrm{NaOH}: \mathrm{Na}_{2} \mathrm{CO}_{3}: \mathrm{H}_{2} \mathrm{O}$ by weight is $5: 2: 100$, respectively) at $85^{\circ} \mathrm{C}$ for $1.5 \mathrm{~h}$, and then washed with deionized water. The degreased Ti piece was etched in a HF aqueous solution at room temperature for about $20 \mathrm{~s}$, followed by washing with deionized water. The pretreated $\mathrm{Ti}$ piece was immersed into an aqueous solution containing both $\mathrm{H}_{2} \mathrm{O}_{2}$ and $\mathrm{NaOH}$ in a Teflon-lined autoclave, where the concentration of $\mathrm{H}_{2} \mathrm{O}_{2}$ was in the range from 0 to $15 \%(\mathrm{v} / \mathrm{v})$ and that of $\mathrm{NaOH}$ is fixed at $2 \mathrm{M}$. The sealed autoclave was then kept in an oven at a given temperature ranging from 40 to $120^{\circ} \mathrm{C}$ for a time period of 0.5 to $6 \mathrm{~h}$. In order to investigate the effect of the alkali type on the growth of $\mathrm{TiO}_{2}$ nanowire thin films, $\mathrm{NaOH}$ can be replaced with other alkalis. After treatment, the specimen was removed from the aqueous solution, washed thoroughly with deionized water to remove the alkali, and finally dried in air.

The surface morphology of the films was examined using a scanning electron microscope (SEM, Hitachi S4700 ) operating at $15 \mathrm{kV}$. The chemical composition of the film was characterized by energy-dispersive x-ray spectra (EDS). The energy-dispersive x-ray spectrometer was attached to SEM and operated at a low voltage of $8 \mathrm{kV}$. The phase composition of the films was analyzed by x-ray diffraction (XRD), which was performed on a Thermo ARL XTRA x-ray diffractometer using $\mathrm{Cu} \mathrm{K} \alpha \mathrm{X}$-ray source. The microstructure investigations were performed with a Tecnai G2 F30 S-Twin transmission electron microscopy (TEM) operating at $300 \mathrm{kV}$.

\section{Results and discussion}

\section{Effect of $\mathrm{H}_{2} \mathrm{O}_{2}$ concentration, temperature, and alkali type on the growth of titanate nanowire films}

Figure 1 shows the SEM images of the films formed at $80^{\circ} \mathrm{C}$ for $6 \mathrm{~h}$ in $\mathrm{NaOH}(2 \mathrm{M})-\mathrm{H}_{2} \mathrm{O}_{2}$ solutions with different $\mathrm{H}_{2} \mathrm{O}_{2}$ concentrations. As shown in Fig. 1(a), in the absence of $\mathrm{H}_{2} \mathrm{O}_{2}$, chemical etching of Ti by $2 \mathrm{M} \mathrm{NaOH}$ only leads to the generation of a porous film. The porous layer contains large amount of oxygen compared to the pretreated Ti substrate (see Fig. 2(a)), but the observation of negligible amount of $\mathrm{Na}$ demonstrates that the film is titanium oxide. The atomic ratio of Ti:O calculated is about $2: 1$, much higher than the value of 1:2 for $\mathrm{TiO}_{2}$ or $2: 3$ for $\mathrm{Ti}_{2} \mathrm{O}_{3}$, suggesting that the film is very thin and the signal of underlying Ti substrate is also collected during EDS measurement. When $\mathrm{H}_{2} \mathrm{O}_{2}$ $(7.5 \% \mathrm{v} / \mathrm{v})$ is added, one-dimensional nanostructures appear (Fig. 1(b)) although they are not totally separated from each other. With the rise in $\mathrm{H}_{2} \mathrm{O}_{2}$ concentration, the shape of these one-dimensional nanostructures become more defined (Fig. 1(c)), and well-shaped one-dimensional nanostructures are observed when the $\mathrm{H}_{2} \mathrm{O}_{2}$ concentration reaches $15 \%$ v/v (Fig. $1(\mathrm{~d})$ ). The investigation by TEM confirms that these 

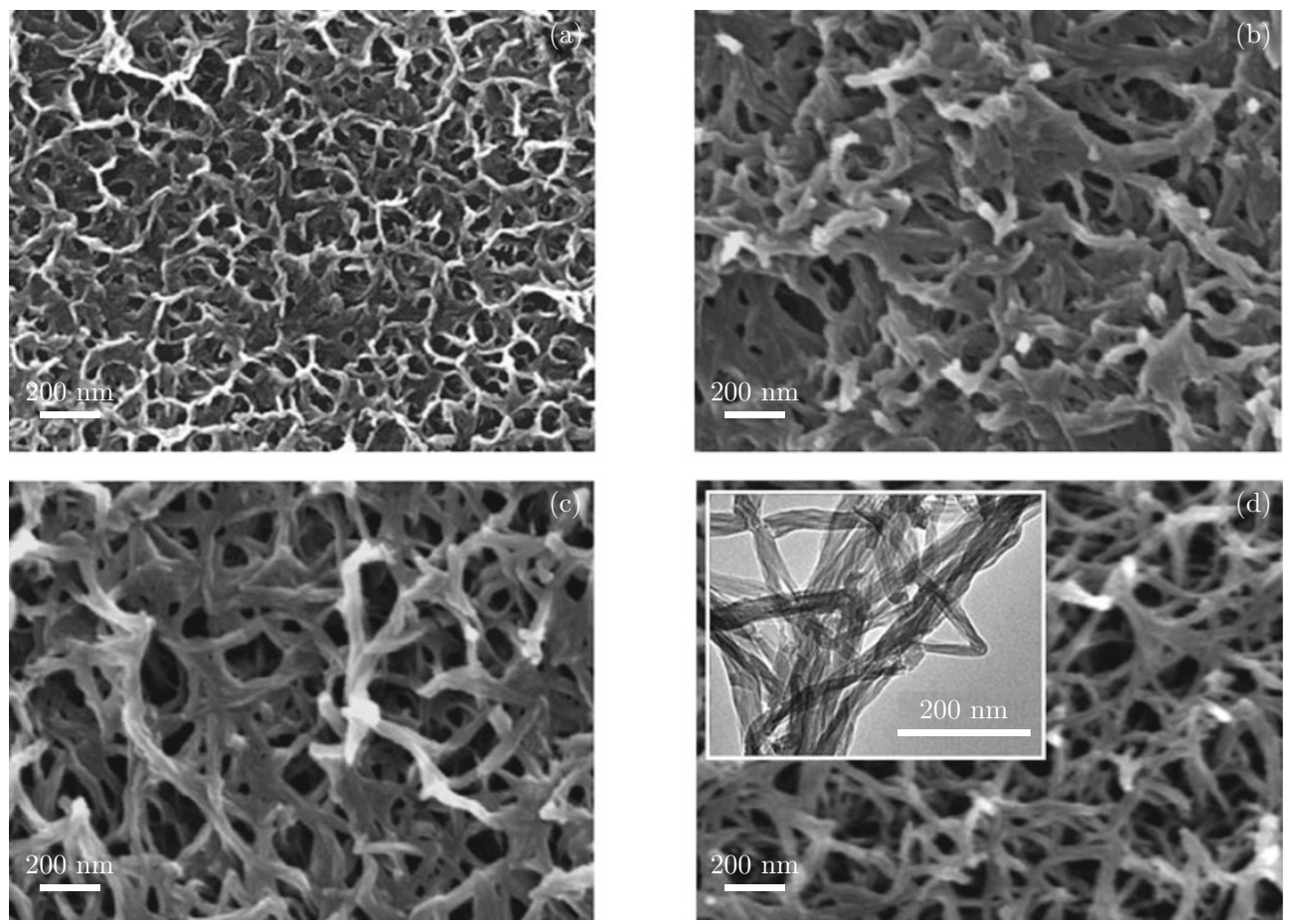

Fig. 1 SEM images of the films formed by treating Ti foils at $80^{\circ} \mathrm{C}$ for $6 \mathrm{~h}$ in $\mathrm{H}_{2} \mathrm{O}_{2}-\mathrm{NaOH}(2 \mathrm{M})$ mixed solutions with different $\mathrm{H}_{2} \mathrm{O}_{2}$ concentrations. (a) 0 , (b) $7.5 \% \mathrm{v} / \mathrm{v}$, (c) $11.25 \% \mathrm{v} / \mathrm{v}$, and (d) $15 \% \mathrm{v} / \mathrm{v}$. Inset of Fig. 2(d) is the corresponding TEM image of the nanowires.
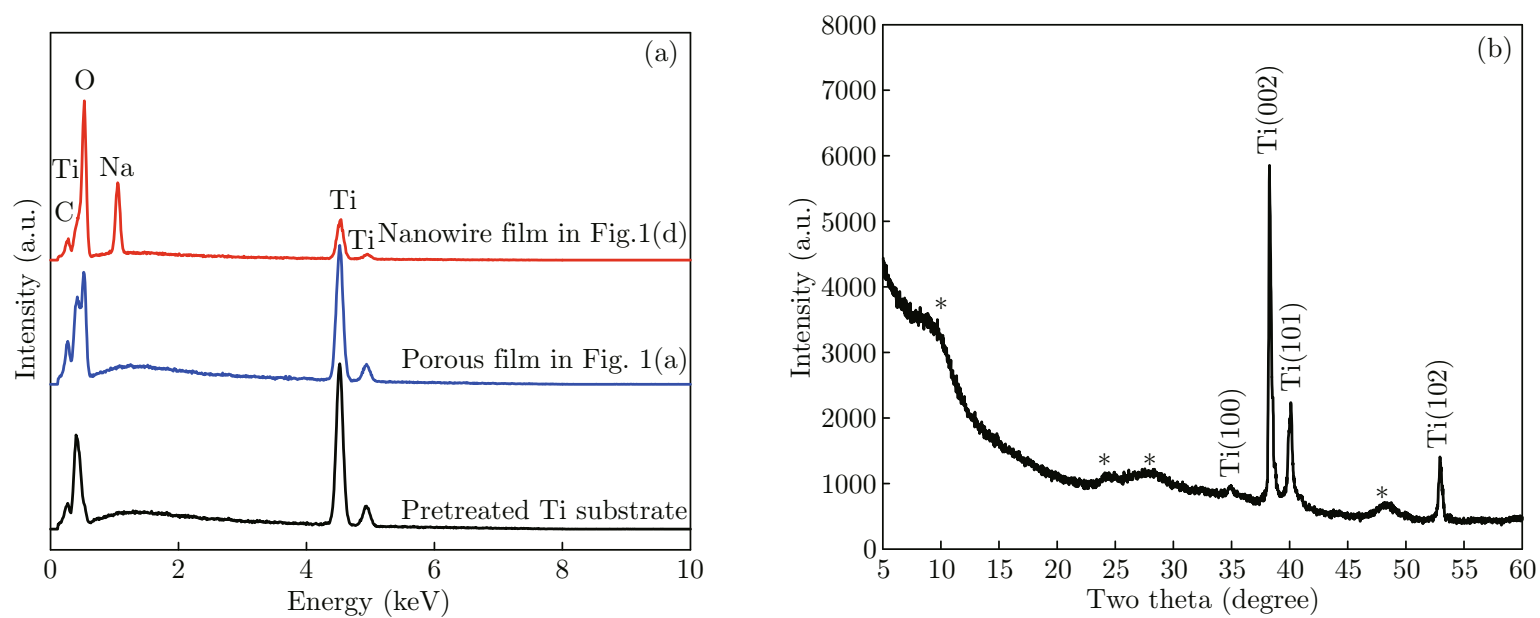

Fig. 2 (a) EDS spectra of pretreated Ti substrate, porous film formed in $\mathrm{NaOH}$ solution, and nanowire film formed in $\mathrm{H}_{2} \mathrm{O}_{2}{ }^{-}$ $\mathrm{NaOH}$ mixed solution, and (b) XRD pattern of the nanowire film formed by treating Ti foils in $\mathrm{H}_{2} \mathrm{O}_{2}(15 \% \mathrm{v} / \mathrm{v})-\mathrm{NaOH}(2 \mathrm{M})$ mixed solutions for $6 \mathrm{~h}$ at $80^{\circ} \mathrm{C}$.

one-dimensional nanostructures are nanowires (see inset of Fig. 1(d)). In addition, in compared with the film formed in the absence of $\mathrm{H}_{2} \mathrm{O}_{2}$, the nanowire film contains large amount of $\mathrm{Na}$ (see Fig. 2(a)), indicating that the nanowires formed might be mainly in the form of titanate. The atomic ratio of Na:Ti:O calculated from the EDS spectrum is about 0.38:1:2.52. Since the atomic ratios of $\mathrm{Na}$ :Ti:O are, respectively, 2:1:3 for $\mathrm{Na}_{2} \mathrm{TiO}_{3}, 1: 1: 3$ for $\mathrm{NaHTiO}_{3}, 2: 1: 2.3$ for $\mathrm{Na}_{2} \mathrm{Ti}_{3} \mathrm{O}_{7}$, and 1:1:2.3 for $\mathrm{NaHTi}_{3} \mathrm{O}_{7}$, we speculate that the nanowires formed are mainly in the form of $\mathrm{Na}_{\mathrm{x}} \mathrm{H}_{2-\mathrm{x}} \mathrm{Ti}_{3} \mathrm{O}_{7}$ where $\mathrm{Na}$ is lacking. The excess of $\mathrm{O}$ observed might be related to the contamination of oxygen-containing compounds on the film surface. The formation of titanate nanowire film is also confirmed by XRD measurement (see Fig. 2(b)). Besides the characteristic peaks of $\mathrm{Ti}$ substrate, some broad peaks at $2 \theta$ of about $9.1^{\circ}, 24.4^{\circ}$, $28.1^{\circ}$, and $48.2^{\circ}$ (indicated by stars), which can be attributed to trititanate $[9,11]$, are also be observed in the XRD pattern of the nanowire film. 
The above experimental results suggest that the presence of $\mathrm{H}_{2} \mathrm{O}_{2}$ is necessary for the formation of nanowire-like materials and sufficient amount of $\mathrm{H}_{2} \mathrm{O}_{2}$ is needed to produce well-shaped nanowires. It is well known that the exposure of Ti foil to $\mathrm{H}_{2} \mathrm{O}_{2}$ solution will lead to the formation of titanium peroxide gel $\mathrm{Ti}(\mathrm{OH})_{2} \mathrm{O}_{2}$ on Ti substrate [25]. Such a Tiperoxy gel can be decomposed into amorphous hydrate titania $\mathrm{TiO}_{2} \cdot n \mathrm{H}_{2} \mathrm{O}$ layer $[25,26]$. In the absence of $\mathrm{H}_{2} \mathrm{O}_{2}$, the reaction between $\mathrm{Ti}$ and $\mathrm{H}_{2} \mathrm{O}$ can also lead to the formation of a very thin passivation layer: $\mathrm{Ti}+3 \mathrm{H}_{2} \mathrm{O}=\mathrm{TiO}_{2} \cdot \mathrm{H}_{2} \mathrm{O}+2 \mathrm{H}_{2}$. Under alkaline environment, the hydrated titania layer may react with $\mathrm{NaOH}$ to form $\mathrm{NaHTiO}_{3}$. The formed $\mathrm{NaHTiO}_{3}$ is then expected to be transformed into Na-lacking titanate via the following condensation reaction: $3 \mathrm{NaHTiO}_{3}+(1-$ x) $\mathrm{H}_{2} \mathrm{O}=\mathrm{Na}_{\mathrm{x}} \mathrm{H}_{2-\mathrm{x}} \mathrm{Ti}_{3} \mathrm{O}_{7}+(3-\mathrm{x}) \mathrm{NaOH}$. Since the solubility of titanate in water is very low, titanate may grow on the Ti surface via heterogeneous deposition. However, the observation of titanium oxide film in the absence of $\mathrm{H}_{2} \mathrm{O}_{2}$ demonstrates that the dissolution of the passivation layer by $\mathrm{NaOH}$ does not result in the deposition of titanate on the Ti surface. We speculate that the occurrence of the condensation reaction might need a higher concentration of $\mathrm{NaHTiO}_{3}$ in the solution. It is possible that in the absence of $\mathrm{H}_{2} \mathrm{O}_{2}$ the dissolution of the very thin passivation layer by $\mathrm{NaOH}$ cannot produce a $\mathrm{NaHTiO}_{3}$ solution with its concentration high enough for the formation of $\mathrm{Na}_{\mathrm{x}} \mathrm{H}_{2-\mathrm{x}} \mathrm{Ti}_{3} \mathrm{O}_{7}$. In contrast, the presence of $\mathrm{H}_{2} \mathrm{O}_{2}$ can produce sufficient amount of
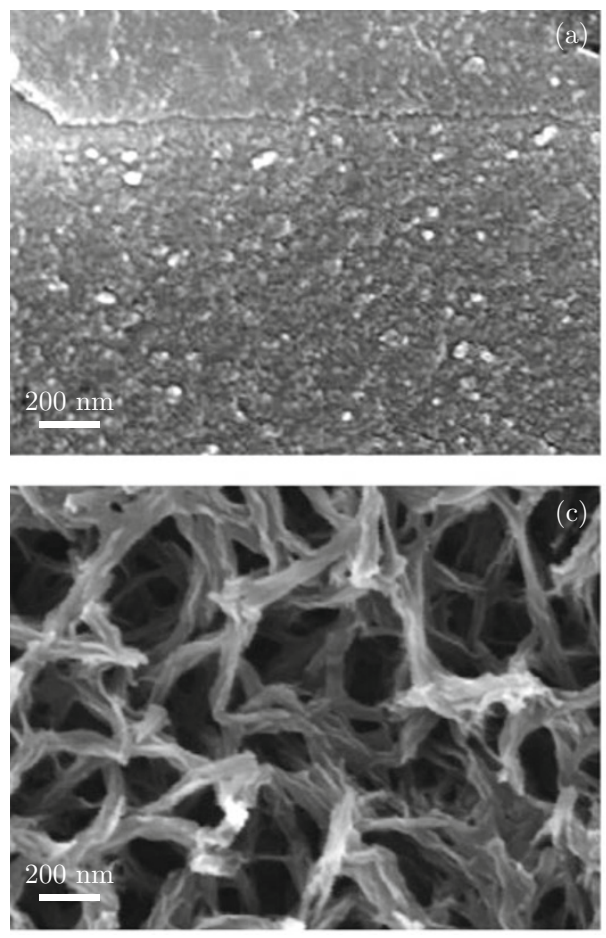

hydrated titania for the formation of $\mathrm{Na}_{\mathrm{x}} \mathrm{H}_{2-\mathrm{x}} \mathrm{Ti}_{3} \mathrm{O}_{7}$. From a kinetic point of view, the rise in $\mathrm{H}_{2} \mathrm{O}_{2}$ concentration may increase the formation rate of the hydrated titania layer, and thus for a given time period more hydrated titania can be provided for the formation of titanate. Accordingly, the presence of $\mathrm{H}_{2} \mathrm{O}_{2}$ with high concentration favors the formation of titanate films.

Since the treatment temperature may influence all the processes involved in the formation of titanate nanowires, the temperature effect on the formation of nanowire films has also been investigated. Figure 3 shows the SEM images of the films formed in a mixed solution of $\mathrm{NaOH}(2 \mathrm{M})$ and $\mathrm{H}_{2} \mathrm{O}_{2}(15 \% \mathrm{v} / \mathrm{v})$ for $6 \mathrm{~h}$ at different temperatures. At a temperature of $40^{\circ} \mathrm{C}$, only a compact layer which is composed of nanoparticles is observed (Fig. 3(a)). When the temperature is raised to $60^{\circ} \mathrm{C}$, however, large amount of nanowires are clearly seen (Fig. 3(b)), suggesting that the nanowire growth can occur at a temperature as low as $60^{\circ} \mathrm{C}$. With a further rise in temperature, the size of the nanowires increases gradually. For example, the average diameter of the nanowires increases from $\sim 30 \mathrm{~nm}$ at $60^{\circ} \mathrm{C}$ to $\sim 70 \mathrm{~nm}$ at $100^{\circ} \mathrm{C}$ (see Fig. 3(c)). It should be pointed out that, however, when the temperature reaches $100^{\circ} \mathrm{C}$ or above, the surface of the nanowires becomes very unsmooth, especially under the hydrothermal conditions (namely $120^{\circ} \mathrm{C}$ ). The shape of the nanostructures formed at $120^{\circ} \mathrm{C}$ is more similar to short nanobelts than nanowires (Fig. 3(d)), hinting that in $\mathrm{NaOH}-\mathrm{H}_{2} \mathrm{O}_{2}$ solutions with a low $\mathrm{NaOH}$ concentration the hydrothermal
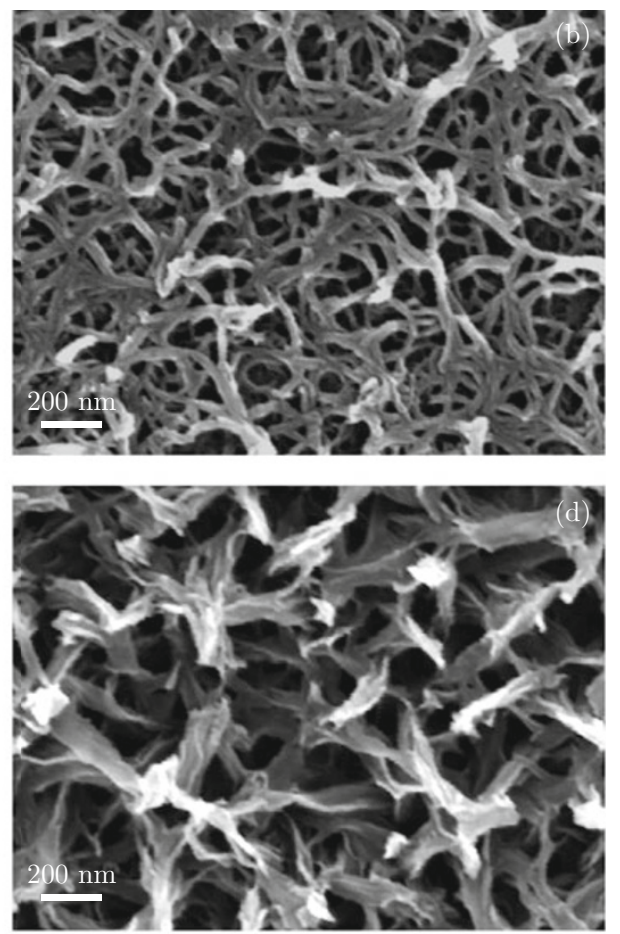

Fig. 3 SEM images of the films formed by treating Ti foils in $\mathrm{H}_{2} \mathrm{O}_{2}(15 \% \mathrm{v} / \mathrm{v})-\mathrm{NaOH}(2 \mathrm{M})$ mixed solutions for $6 \mathrm{~h}$ at different temperatures: (a) $40^{\circ} \mathrm{C}$, (b) $60^{\circ} \mathrm{C}$, (c) $100^{\circ} \mathrm{C}$, and (d) $120^{\circ} \mathrm{C}$. 
treatment is not favorable for the formation of nanowire film.

To gain inside into the formation mechanism of titanate nanowires film, we have further clarified the role of $\mathrm{NaOH}$ in the formation of nanowire film by replacing $\mathrm{NaOH}$ with $\mathrm{NaCl}, \mathrm{NH}_{3} \cdot \mathrm{H}_{2} \mathrm{O}$, a mixture of $\mathrm{NH}_{3} \cdot \mathrm{H}_{2} \mathrm{O}$ and $\mathrm{NaCl}, \mathrm{KOH}$, or $\mathrm{Ba}(\mathrm{OH})_{2}$. As shown in Fig. 4(a), after treating $\mathrm{Ti}$ foil in the $\mathrm{NaCl}-\mathrm{H}_{2} \mathrm{O}_{2}$ solution, we can only find short rod-like materials on the Ti substrate. The observed morphology is a little similar to that of the film obtained in the case where only $\mathrm{H}_{2} \mathrm{O}_{2}$ aqueous solution is used (see Fig. 4(b)). If the Ti foil is treated in a $\mathrm{H}_{2} \mathrm{O}_{2}-\mathrm{NH}_{3} \cdot \mathrm{H}_{2} \mathrm{O}$ mixture, a compact film comprised of nanoparticles will grow (see Fig. 4(c)). These results indicate that only the existence of $\mathrm{Na}^{+}$or $\mathrm{OH}^{-}$in the solution cannot lead to the formation of nanowire film. However, we have found that even though the Ti foil is treated in a $\mathrm{NaCl}-\mathrm{H}_{2} \mathrm{O}_{2}-\mathrm{NH}_{3} \cdot \mathrm{H}_{2} \mathrm{O}$ mixture, nanoparticle film rather than nanowire film is formed (see Fig. 4(d)), hinting that in order to produce nanowire film the alkali might exist in the form of hydroxide. Further investigation shows that nanowire film can grow in a $\mathrm{KOH}-\mathrm{H}_{2} \mathrm{O}_{2}$ mixed solution (Fig. 4(e)) whereas dense nanoparticle film is produced in a $\mathrm{Ba}(\mathrm{OH})_{2}-\mathrm{H}_{2} \mathrm{O}_{2}$ mixture (Fig. 4(f)). Since both $\mathrm{NaOH}$ and $\mathrm{KOH}$ are alkali metal hydroxides which can react with $\mathrm{TiO}_{2}$ to form a layer-structured alkali metal titanate, it is inferred that the formation of nanowire film is strongly dependant on the structure of the titanate formed, and titanate with a layered structure favors the nanowire growth.
Formation process and growth mechanism of titanate nanowire films

To substantially understand the formation process of titanate nanowire, we have examined the morphology of the films formed at different growth stages. After chemically etched in a HF aqueous solution, the surface of $\mathrm{Ti}$ is not flat, but at small scale we can observe a relatively smooth surface (Fig. 5(a)). When the Ti foil is treated in a $\mathrm{NaOH}-\mathrm{H}_{2} \mathrm{O}_{2}$ mixed solution for $0.5 \mathrm{~h}$, an interesting terraces-like morphology appears (Fig. 5(b)). The terraces are obviously built by many sheet-like materials which are actually comprised of nanoparticles (see inset of Fig. 5(b)). We find that the sizes of these sheetlike materials may increase with growth time. As shown in Fig. 5(c), when the treatment duration is prolonged to $1 \mathrm{~h}$, the sizes of the sheet-like materials are much larger than those observed in Fig. 5(b). Furthermore, the sizes of the nanoparticles within the sheets also become larger (see inset of Fig. 5(c)). The observation of these sheet-like materials might be related to the fact that alkali metal titanate has a layered structure and thus favors the formation of sheet-like materials. As the treatment duration is raised to $1.5 \mathrm{~h}$, these titanate sheets begin to evolve into nanowire-like materials (Fig. 5(d)). The high-magnification image (see inset of Fig. 5(d)) where clear boundaries (some boundaries are indicated by arrows) between elongated particles (or nanowire-like materials) are observed provides a clue to the evolution of titanate sheets into nanowires. We
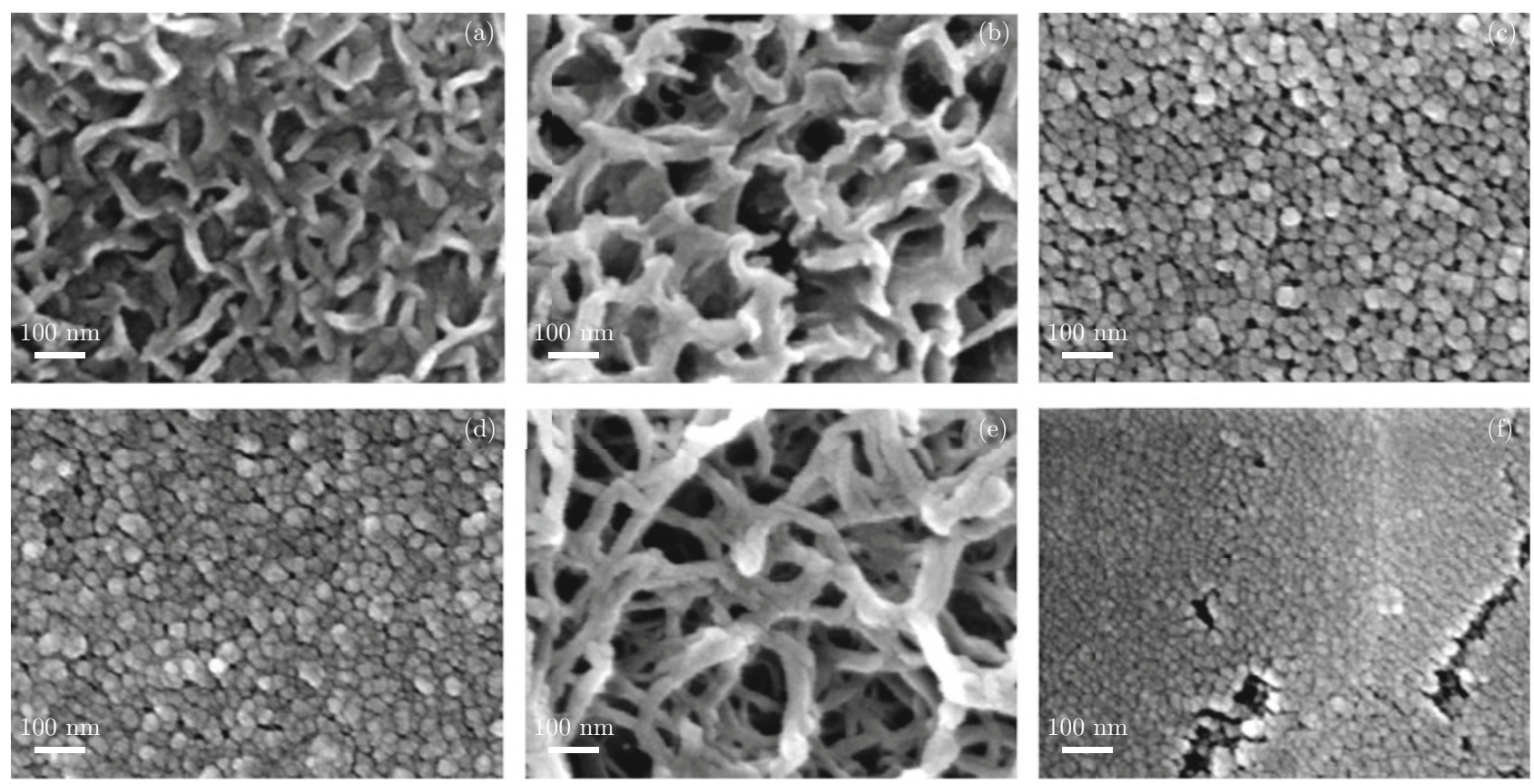

Fig. 4 SEM images of the films formed by treating Ti foils at $80^{\circ} \mathrm{C}$ for $6 \mathrm{~h}$ in different solutions with the concentration of $\mathrm{H}_{2} \mathrm{O}_{2}$ being fixed at $15 \% \mathrm{v} / \mathrm{v}$ : (a) $\mathrm{NaCl}(2 \mathrm{M})-\mathrm{H}_{2} \mathrm{O}_{2}$, (b) $\mathrm{H}_{2} \mathrm{O}_{2}$, (c) $\mathrm{NH}_{3} \cdot \mathrm{H}_{2} \mathrm{O}(18.5 \% \mathrm{v} / \mathrm{v})-\mathrm{H}_{2} \mathrm{O}_{2}$, (d) NaCl$(2 \mathrm{M})-\mathrm{NH} 3 \cdot \mathrm{H}_{2} \mathrm{O}(18.5 \% \mathrm{v} / \mathrm{v})-$ $\mathrm{H}_{2} \mathrm{O}_{2}$, (e) $\mathrm{KOH}(2 \mathrm{M})-\mathrm{H}_{2} \mathrm{O}_{2}$, and (f) $\mathrm{Ba}(\mathrm{OH})_{2}(1.5 \mathrm{M})-\mathrm{H}_{2} \mathrm{O}_{2}$. 

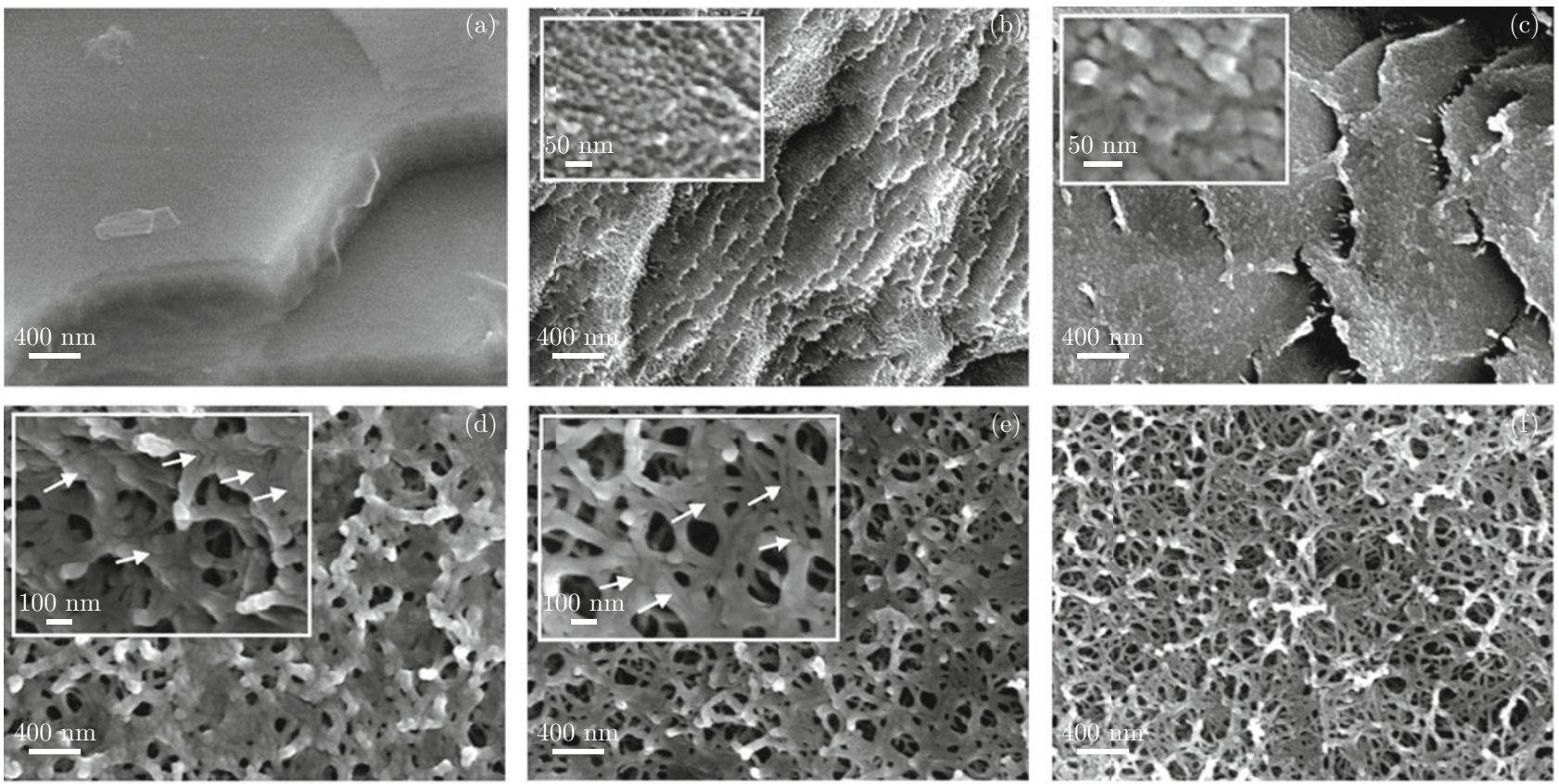

Fig. 5 SEM images of the films formed by treating Ti foils in $\mathrm{H}_{2} \mathrm{O}_{2}(15 \% \mathrm{v} / \mathrm{v})-\mathrm{NaOH}(2 \mathrm{M})$ mixed solution at $80^{\circ} \mathrm{C}$ for different durations: (a) 0, (b) 0.5 h, (c) 1 h, (d) 1.5 h, (e) 2 h, and (f) 4 h. Insets of Fig. 5(b), 5(c), 5(d) and 5 (e) are the high magnification images of corresponding materials.
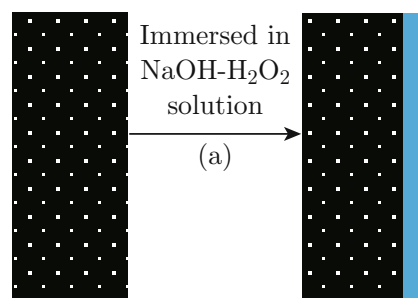

Ti foil

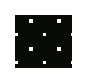

Titanate

...

・.

...
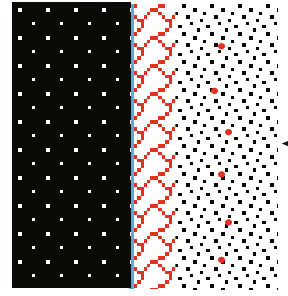

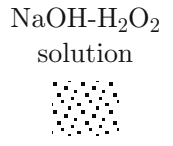

Titanate sheets<smiles>C1#CC#C1</smiles>

$\frac{\begin{array}{c}\text { Splitting of } \\ \text { titanate sheets }\end{array}}{\text { (e) }}$
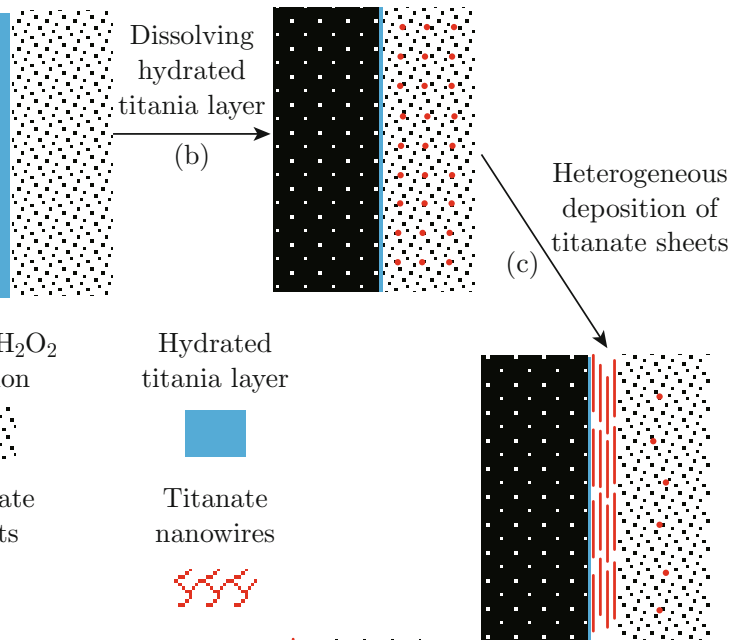

Hydrated titania layer

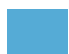

Titanate nanowires 552
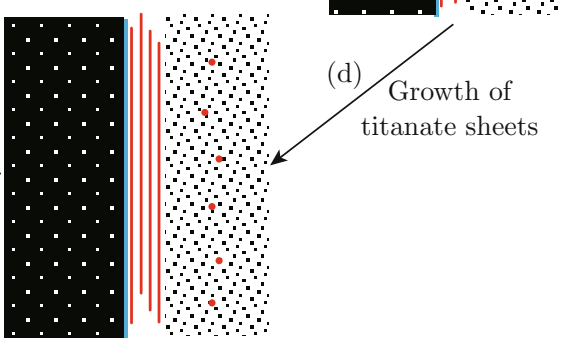

Fig. 6 A scheme for the formation of titanate nanowires films in $\mathrm{NaOH}-\mathrm{H}_{2} \mathrm{O}_{2}$ aqueous solutions.

infer from these images (namely insets of Fig. 5(b), 5(c), and $5(\mathrm{~d}))$ that the nanoparticles within the sheets selfassembly into elongated particles (or nanowire-like materials) and then a "splitting" process along the boundaries between elongated particles (or nanowire-like ma- terials) leads to the formation of nanowires. As the growth time increases to $2 \mathrm{~h}$ (see Fig. 5(e) and its inset with some boundaries being indicated by arrows), the splitting process continues and thus the diameter of the nanowire becomes smaller and smaller, with the shape 
of the nanowire being more defined. When the duration is raised to $4 \mathrm{~h}$, well-structured nanowire film is formed (Fig. 5(f)).

Based on our above experimental results, we propose a possible mechanism for growth of titanate nanowire film in $\mathrm{NaOH}-\mathrm{H}_{2} \mathrm{O}_{2}$ mixed solution at low temperature (Fig. 6). Firstly, when the Ti foil is immersed into in $\mathrm{NaOH}-\mathrm{H}_{2} \mathrm{O}_{2}$ mixed solution, the growth of hydrated titania layer will occur mainly through the following reactions (step (a) in Fig. 6), namely $\mathrm{Ti}+\mathrm{H}_{2} \mathrm{O}_{2}+2 \mathrm{H}_{2} \mathrm{O}=\mathrm{Ti}(\mathrm{OH})_{2} \mathrm{O}_{2}+\mathrm{H}_{2}$ and $\mathrm{Ti}(\mathrm{OH})_{2} \mathrm{O}_{2} \rightarrow \mathrm{Ti}(\mathrm{OH}) \mathrm{O} \rightarrow \mathrm{Ti}(\mathrm{OH}) x \rightarrow \mathrm{TiO}_{2} \cdot n \mathrm{H}_{2} \mathrm{O}$ $[25,26]$. Secondly, the presence of $\mathrm{NaOH}$ in the mixed solution may dissolve the hydrated titania layer to form $\mathrm{NaHTiO}_{3}$ which is then converted to titanate via a condensation reaction (step (b) in Fig. 6). Thirdly, the low solubility of titanate in water makes it possible for titanate to precipitate on the Ti surface via heterogeneous deposition. Since titanate possesses a layered structure, it tends to form sheet-like structure upon its deposition on the Ti substrate. As the heterogeneous deposition of titanate continues, the successively grown titanate sheets will stack one upon another and thus exhibits a terraces-like morphology (steps (c) and (d) in Fig. 6). Finally, the titanate sheets formed under our experimental conditions do not evolve into nanotubes by rolling up themselves. Instead, each titanate sheet is split into nanaowires and thus forms a thin nanowire layer. All these nanowire layers finally construct a nanowire film with net-like structure (step (e) in Fig. 6).

\section{Conclusion}

We have presented a study on the synthesis and growth mechanism of titanate nanowire films in alkali$\mathrm{H}_{2} \mathrm{O}_{2}$ aqueous solutions with an alkali concentration of $2 \mathrm{M}$ at low temperature. It is shown that the role of $\mathrm{H}_{2} \mathrm{O}_{2}$ is to provide sufficient amount of hydrated titania for the formation of $\mathrm{Na}_{2} \mathrm{Ti}_{3} \mathrm{O}_{7}$ and the deposition of titanate sheets is through heterogeneous deposition. The nanowire growth is strongly dependant on the alkali used, and its formation is via a splitting mechanism, by which each of the formed titanate sheets is converted into a thin nanowire layer.

\section{Acknowledgement}

This work was supported by the Natural Science Foundation of Zhejiang Province (No. LY12B07011).

\section{References}

[1] C. K. Lee, M. D. Lyu, S. S Liu and H. C. Chen, "The synthetic parameters for the preparation of nan- otubular titanate with highly photocatalytic activity", J. Taiwan Inst. Chem. Engrs. 40(4), 463-470 (2009). http://dx.doi.org/10.1016/j.jtice.2008.12.007

[2] Y. C. Pu, Y. C. Chen and Y. J. Hsu, "Au-decorated $\mathrm{Na}_{\mathrm{x}} \mathrm{H}_{2-\mathrm{x}} \mathrm{Ti}_{3} \mathrm{O}_{7}$ nanobelts exhibiting remarkable photocatalytic properties under visible-light illumination", Appl. Catal. B 97(3-4), 389-397 (2010). http://dx. doi.org/10.1016/j.apcatb.2010.04.023

[3] X. G. Xu, X. Ding, Q. Chen and L. M. Peng, "Modification of electronic, optical, and magnetic properties of titanate nanotubes by metal intercalate", Phys. Rev. B 75(3), 035423-035434 (2007). http://dx.doi.org/ 10.1103/PhysRevB.75.035423

[4] D. J. Yang, Z. F. Zheng, H. W. Liu, H. Y. Zhu, X. B. Ke, Y. Xu, D. Wu and Y. Sun, "Layered titanate nanofibers as efficient adsorbents for removal of toxic radioactive and heavy metal ions from water", J. Phys. Chem. C 112(42), 16275-16280 (2008). http:// dx.doi.org/10.1021/jp803826g

[5] L. Zhao, J. G. Yu, J. J. Fan, P. C. Zhai and S. M. Wang, "Dye-sensitized solar cells based on ordered titanate nanotube films fabricated by electrophoretic deposition method", Electrochem. Comm. 11(10), 20522055 (2009). http://dx.doi.org/10.1016/j.elecom. 2009.08 .050

[6] H. Tokudome and M. Miyauchi, "Electrochromism of titanate-based nanotubes", Angew. Chem. Int. Ed. 44(13), 1974-1977 (2005). http://dx.doi.org/ 10. 1002 /anie. 200462448

[7] S. Bela, A. S. W. Wong and G. W. Ho, "Hydrolysis and ion exchange of titania nanoparticles towards large-scale titania and titanate nanobelts for gas sensing applications", J. Phys. D 43(3), 035401-035406 (2010). http://dx.doi.org/10.1088/0022-3727/43/ $3 / 035401$

[8] D. Wu, J. Liu, X. N. Zhao, A. D. Li, Y. F. Chen and N. B. Ming, "Sequence of events for the formation of titanate nanotubes, nanofibers, nanowires, and nanobelts", Chem. Mater. 18(2), 547-553 (2006). http://dx.doi.org/10.1021/cm0519075

[9] E. Horvath, A. Kukovecz, Z. Konya and I. Kiricsi, "Hydrothermal conversion of self-assembled titanate nanotubes into nanowires in a revolving autoclave", Chem. Mater. 19(4), 927-931 (2007). http://dx.doi.org/10. $1021 / \mathrm{cm} 062413 \mathrm{q}$

[10] C. W. Peng, M. Richard-Plouet, T. Y. Ke, C. Y. Lee, H. T. Chiu, C. Marhic, E. Puzenat, F. Lemoigno and L. Brohan, "Chimie douce route to sodium hydroxo titanate nanowires with modulated structure and conversion to highly photoactive titanium dioxides", Chem. Mater. 20(23), 7228-7236 (2008). http://dx. doi.org/10.1021/cm8007039

[11] J. Q. Huang, Y. G. Cao, Q. F. Huang, H. He, Y. Liu, W. Guo and M. C. Hong, "High-temperature formation of titanate nanotubes and the transformation mechanism of nanotubes into nanowires", Cryst. Growth Design 9(8), 3632-3637 (2009). http://dx. doi.org/10.1021/cg900381h

[12] J. S. Xu, H. Zhang, W. B. Li, J. Zhang, X. Y. Liu, X. K. He, D. L. Xu, J. H. Qian and L. Liu, "Hydrothermal 
synthesis and characterisation of potassium/sodium titanate nanofibres at different temperatures", Micro Nano Lett. 7(7), 654-657 (2012). http://dx.doi.org/ $10.1049 / \mathrm{mnl} .2012 .0376$

[13] M.-J. Li, Z.-Y. Chi and Y.-C. Wu, "Morphology, chemical composition and phase transformation of hydrothermal derived sodium titanate", J. Am. Ceram. Soc. 95(10), 3297-3304 (2012). http://dx.doi.org/ 10.1111/j.1551-2916.2012.05330.x

[14] T. Kasuga, M. Hiramatsu, A. Hoson, T. Sekino and K. Niihara, "Formation of titanium oxide nanotube", Langmuir 14(12), 3160-3163 (1998). http://dx.doi. org/10.1021/la9713816

[15] J. I. Kim, S. Y. Lee and J. C. Pyun, "Characterization of photocatalytic activity of $\mathrm{TiO}_{2}$ nanowire synthesized from Ti-plate by wet corrosion process", Current Appl. Phys. 9(4), e252-e255 (2009). http://dx. doi.org/10.1016/j.cap. 2009.06.055

[16] M. Yada, Y. Inoue, M. Uota, T. Torikai, T. Watari, I. Noda and T. Hotokebuchi, "Plate, wire, mesh, microsphere, and microtube composed of sodium titanate nanotubes on a titanium metal template", Langmuir 23(5), 2815-2823 (2007). http://dx.doi. org/10.1021/la062654c

[17] Y. Inoue, I. Noda, T. Torikai, T. Watari , T. Hotokebuchi and M. Yada, " $\mathrm{TiO}_{2}$ nanotube, nanowire, and rhomboid-shaped particle thin films fixed on a titanium metal plate", J. Solid State Chem. 183(1), 57-64 (2010). http://dx.doi.org/10.1016/j.jssc. 2009.10.028

[18] B. Chi, E. S. Victorio, T. Jin, B. Chi, E. S. Victorio and T.Jin, "Synthesis of $\mathrm{TiO}_{2}$-based nanotube on $\mathrm{Ti}$ substrate by hydrothermal treatment", J. Nanosci. Nanotechol. 7(2), 668-672 (2007). http://dx.doi.org/10. 1166/jnn. 2007.147

[19] Y. P. Guo, N. H. Lee, H. J. Oh, C. R. Yoon, K. S. Park, H. G. Lee, K. S. Lee and S. J. Kim, "Structuretunable synthesis of titanate nanotube thin films via a simple hydrothermal process", Nanotechnol. 18(29),
295608-295615 (2007). http://dx.doi.org/10.1088/ 0957-4484/18/29/295608

[20] M. Kitano, R. Mitsui, D. R. Eddy, Z. M. A. ElBahy, M. Matsuoka, M. Ueshima and M. Anpo, "Synthesis of nanowire $\mathrm{TiO}_{2}$ thin films by hydrothermal treatment and their photoelectrochemical properties", Catal. Lett. 119(3-4), 217-221 (2007). http://dx.doi. org/10.1007/s10562-007-9243-1

[21] A. M. Hu, X. Zhang, K. D. Oakes, P. Peng, Y. N. Zhou and M. R. Servos, "Hydrothermal growth of free standing $\mathrm{TiO}_{2}$ nanowire membranes for photocatalytic degradation of pharmaceuticals", J. Hazard. Mater. 189(1-2), 278-285 (2011). http://dx.doi.org/ 10.1016/j.jhazmat. 2011.02.033

[22] Y. F. Zhu, R. G. Du, W. Chen, H. Q. Qi and C. J. Lin, "Photocathodic protection properties of three-dimensional titanate nanowire net work films prepared by a combined sol-gel and hydrothermal method", Electrochem. Comm. 12(11), 16261629 (2010). http://dx.doi.org/10.1016/j.elecom. 2010.09.011

[23] Y. H. Wu, M. C. Long, W. M. Cai, S. D. Dai, C. Chen, D. Y. Wu and J. Bai, "Preparation of photocatalytic anatase nanowire films by in situ oxidation of titanium plate", Nanotechnol. 20(18), 185703-185710 (2009). http://dx.doi.org/10.1088/0957-4484/20/ $18 / 185703$

[24] X. P. Bao, Z. J. Liu and D. Y. Lu, "A study on $\mathrm{TiO}_{2}$ based nanowire thin films prepared by chemical oxidation", J. Zhejiang Univ. (Sci. edition) 39, 407-410 (2012).

[25] P. Tengvall, H. Elwing and I. Lundstrom, "Titanium gel made from metallic titanium and hydrogen peroxide", J. Colloid Interface Sci. 130(2), 405-413 (1989). http://dx.doi.org/10.1016/ 0021-9797 (89) 90117-3

[26] J. M. Wu and T. W. Zhang, "Large-scale preparation of ordered titania nanorods with enhanced photocatalytic activity", Langmuir 21(15), 6995-7002 (2005). http://dx.doi.org/10.1021/la0500272 